\title{
The Use of Cloud E-Learning Platform to ENHANCE EFFICIENCY OF HOSPITAL IN JOB EDUCATION
}

\author{
Yao-Hsu Tsai, Kuo-Chung Lin and Kai-Ling Chen \\ Department of Hospitality Management, Chung Hua University, Hsinchu, Taiwan
}

\begin{abstract}
Hospital in order to host multimedia content, licenses and staff in-service education in learning, learning platform to promote construction of the clouds. In this study, quantitative research to explore the building through the clouds to enhance the learning platform with the hospital staff in the benefits of the correlation. First, literature review to identify the factors that measure the effectiveness of e-learning. Second, using a questionnaire designed to identify factors that enhance the effectiveness of online learning platform and build the relationship between the cloud-learning platforms to identify design strategies. The again, using these factors to design cloud e-learning platform for hospital. Finally, the assessment review of the applicability of the cloud-learning platform.
\end{abstract}

\section{KEYWORDS}

Cloud E-learning, Public Health, Job Education, IT, Classroom Technology

\section{INTRODUCTION}

With the progresses of IT and network technologies, the hospital in job education teaching methodology is required to updated accordingly. Teaching materials propared by the teachers can no longer satisfy student's needs. Instead, the students have a growing demand for various types of computer software [1]. Thus, a well-equipped e-Cloud classroom installed with the necessary software is expected to enable the students learn to use the computer software for making computer graphics and doing computer-aided layout design, and so as to improve their learning effects.Over a long period of time in the past, the traditionalhospital in job educationing requires the students and the teachers to be present in the same location, at the same time so that the teachers can impart knowledge to the students, and learning can be chieved by discussion and communication.

With the progress of IT and network technologies, we have been moving into the online learning age, and many colleges have set up online learning websites to improve learning effects.Online learning websites is one of the important methods to enhance educational resources. Most of the students not only needs the courses provided by the teachers, they also need to practice using the application software to get hands-on experiences. However, most of the students can not afford the expensive software. Thus, this research is an effort in integrating IT technologies and educational applications with cloud computing concepts and services to set up e-Cloud classroom in order to build up an learning environment in which a student can learn "at any time and any place" (Jian \& Lu, 2010).In order to set up a convenient and all-inclusive IT learning environment which can solve the problems of frequent software upgrading and version changes while minimizing the capital outlay and maintenance costs, e-Cloud classroom is designed to solve all those problems by integrating software and IT resources of all departments of a college. The end result: All teaching resources are fully utilized.This research is designed to explore the appropriateness of e-Cloud teaching in T university. A questionaire survey was conducted to 
provide reference for colleges wishing to apply e-Cloud teaching in the future. The purpose of this reseach is for studying the feasibility of making use e-Cloud technologies in online learning.

\section{REVIEW LITERATURE}

In recent years, e-Learning has been moving forward at a stunning pace so that the Cyberspace is filled with tons of all kinds of online teaching resources. Such online teaching enables a student to learn with no restraint of time and space, and it allows the students to learn effectively various kinds of knowledge and skills. Online learning is a mode of learning which makes use of technology available in the World Wide Web and multimedia fields so that students can access the online teaching materials in a wide variety of digital network resources through simple network interface [3].

The purpose of teaching is for imparting knowledge and skills. The traditional way of hands-on teaching was achieved through teacher's demonstration. After teacher's explanation and demostration, the students were instructed to do the same job as demonstrated by the teacher so as to achieve the purpose of learning. Computer simulation has long been used in the classroom of science, in which the student uses a computer simulation program to "operate" and "observe" the process of an experiment or the different phases of the learning process [7].

On the Cyberspace, it is common to see examples of virtual reality technology being combined with computer-aided teaching. Because of the growing popularity of computer-aided teaching software, computers have been used as tools in computer-aided teaching applications. For example, a student can use a word processing software to create and edit a document, or use a graphics software to create graphic arts, or a spreadsheet software to compile financial data, or MIDI software to compose music. It is obvious that computer software has been widely used in a wide range of fields. Educators and experts in science and technology teaching agree that "learn by doing" is one of the most effective learning methods [6]. As a result, there is an imperative demand for systems which allow students to access the software applications stored on remote nodes of the Internet network for learning purposes [5].

This research is designed to set up an e-Cloud classroom for online teaching and learning environment.Cloud computing technology project started in 2007 as Google and IBM planned to lower the distributed computing costs for academic research purposes. The project aimed at providing an environment for students to develop large scale computing applications [2]. Cloud computing is not a new IT technology, and it evolved from the distributed computing concept which allows the users to do computing by sharing the computing sources scattered on computer networks [2]. Cloud computing can be classified into two categories: Cloud Computing Services and Cloud Computing Technologies. The latter, an extension of the Data Center technology, is used to create and expand the computing resources with the application of virtual computing and automated technologies. The Cloud Computing Services get computing services from remote sites through networks. For example, the Amazon EC2 service, which enables users to install and use different operating systems, was developed under the "Software as a Service" concept.Current cloud computing modes include Infrastructure as a Service (IaaS), Platform as a Service (PaaS) and Software as a Service (SaaS). IaaS focuses on providing computing infrastructure, which includes Data Center, servers hosting, data storage, data/communication security and privacy protection services.

PaaS focuses on platform services, which include sharing software for identity verification and directory services. SaaS, the largest segment of the cloud computing services, focuses on providing software application as as Google Mail, Google Docs, Yahoo Search, Facebook, Twitter etc.With the progress of computer and network technologies, a user can enjoy a wide range of network services such as online shopping, network games, and online banking etc. 
Cloud computing is a method for sharing computing resources available on the Cyberspace (which can be conceptually regarded as the Cloud) and users can access or make use of such resources as data and application software through the Internet. In other words, the goal of cloud computing is that all the resources are stored in the Cloud and a user can access such resources with a device and simple human interface (such as a browser). Based on this concept, this project is an application of the Cloud service to set up an e-Cloud classroom where a student can access various types of online learning software and operating systems with no need to install his/her own application software and operating systems.

\section{SYSTEM ARCHITECTURE}

In order to teach a specific application software or a computing-related course, a computer classroom has to be installed with a specific set of software. To teach a different course, a different set of software needs to be installed in a classroom. In the above case, a classroom serves a single purpose. In case an educational institute teaches a wide range of courses, that means many different computer classrooms need to be set up for the teaching purpose. Such an approach not only requires high cost, but also limits the use of a classroom to a specific course only. Thus, the project initiates a multi-purpose e-Cloud classroom concept (Fig. 1) so that the students can use a wide selection of software applications through the Internet and Web-based network applications. An e-Cloud classroom so configured can meet the requirements for teaching different courses with shared teaching resources to make sure that an educational institution provides high calibre learning environment and the teaching resources are fully utilized.

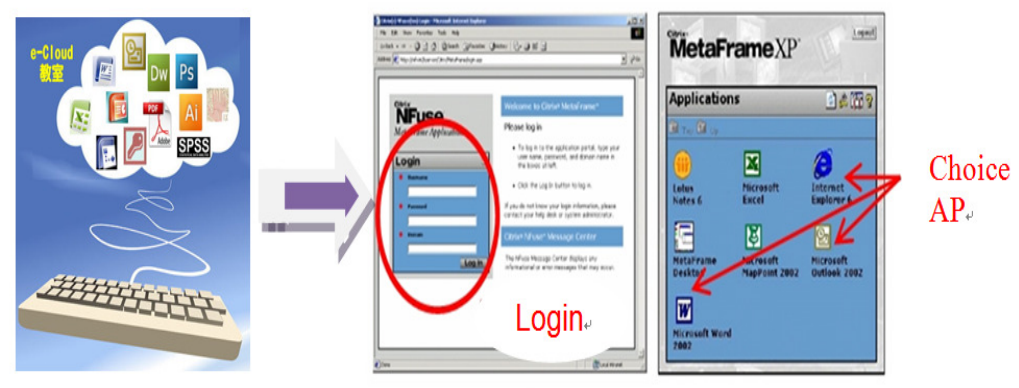

Figure 1. e-Cloud Classroom

An e-Cloud classroom is based on the cloud service, using the network and distributed cluster to configure the e-Cloud classroom (Fig. 2). A student can access the online teaching software using a web browser. This approach can enhance the quality of teaching and keep the students interested. The e-Cloud classroom system of this project is built with the Windows application deliver system, Citrix XenApp, developed by Citrix. Under the Server-Based Computing (SBC) environment, the Citrix Independent Computing Architecture (ICA) serves as a central control of the application programs and offer the application programs as service to the user, who can access the desired applications with a browser [7]. 


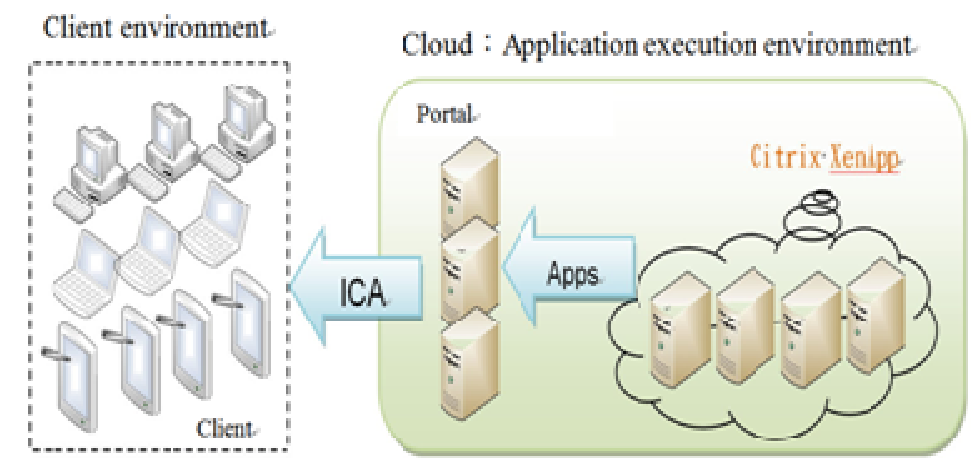

Figure.2 Configuration of e-Cloud Computing Cluster

\section{RESEARCH METHODS}

The research set up an e-Cloud classroom with the cloud computing concept. The classroom enables students to access the application programs through the Internt with browers. Such an approach enhanced the learning effects substantially. This research project was designed to teach the "computer-aided layout lab work" to the 50 students of the T University. The objectives of the course is to teach students to make computer graphic drawings and electic circuit layout skills.

Questionaires were issued to analyze the learning effects. Students are required to compare the current network-based learning platforms and the e-Cloud system, so the students' acceptance of the e-Cloud classroom and its utilization can be analized. The questionaire is divided into three parts: basic info of the respondents, the utilization experience of current network learning platform, and the utilization experience of the e-Cloud classroom.

After the questionaires were returned, the statistic software tool SPSS 12 was used to sort the results. In order to safeguard the effectiveness of the questionaire, ineffective questionaires were sorted out. This study adopts Cronbach's $\alpha$ value to measure the consistency of questioned items. According to the Cronbach's $\alpha$ theory by Nunnally, if the value is greater than 0.7 , it means the validity is high. If the value is between 0.5 and 0.7 , the validity is acceptable. If the value is less than 0.35 , the validity is low. After evaluation of the questionaires, it shows the learners' evaluation of the current network learning platform has an $\alpha$ value of 0.865 , while their evaluation of the e-Cloud classroom has an $\alpha$ value of 0.893 . Both values are greater than the standard value, and demonstrate satisfactory results. It also shows the questionaire of this research is highly reliable.

As shown in Table 1, based on the mean value and standard difference value, learners' acceptance of the e-Cloud classroom is much higher than their acceptance of the network learning platform, in which:

(1) In terms of helpfulness, the highest values are the mean value at 4.46 and the standard difference value at 0.734 . This shows the e-Cloud classroom is most helpful to the students.

(2) The next highest values are of learning effectiveness with the mean value at 4.12 and standard difference value at 0.824 . This shows the e-Cloud classroom remarkably enhanced the learning effectiveness. 
(3) The third highest values are of leaning motivation with the mean value at 4.10 and standard difference value at 0.763 . This shows the e-Cloud classroom remarkably enhanced the learning motivation.

(4) The fourth highest values are of the need with the mean value at 3.88 and standard difference value at 0.918 . This shows the need for e-Cloud classroom is higher than that for network learning platform.

(5) The fifth highest values are of the users' satisfaction with the mean value at 3.70 and standard difference value at 0.763 . This shows the users' satisfaction for e-Cloud classroom is higher than that for network learning platform.

\section{CONCLUSION}

The research discovered the the cloud computing with the e-Cloud Classroom substantially enhanced the effectiveness of learning. The findings are summarized as follows:

(1) In the e-Cloud classroom, the students can learn to use the suitable software according his or her own pace, and this approach helps enhance learning effectiveness considerably.

(2) In the e-Cloud classroom, it enables the students "learn by doing", and thus, enhances the learning effectiveness remarkably.

(3) On one hand, the teacher provides well-planned teaching courses. On the other hand, the students, in order to learn useful courses and achieve self-growth, voluntarily access the e-Cloud classroom. This arrangement prompts the students to learn more actively and achieve better learning effects.

(4) The e-Cloud classroom provides enough learning tools for the students and satisfies the students' need for tools. Such a design helps students learning significantly.

(5) In the e-Cloud classroom, the students no longer worry about insufficient learning tools, and resulting in students' satisfaction.

(6) Today's students are quite familiar with using browsers to access the resources on the Internet. The use of browsers makes their learning quite easy.

(7) Because the students are familiar with computers and network learning platform, making the switch to e-Cloud classroom easy and better learning effects.

(8) The e-Cloud classroom provides flexible learning hours so that the students can select the right hours to use the desired software.

Since this research has attained its objectives, the researchers would like to provide suggestions and observations so that those educational institutions planning to set up e-Cloud classrooms can use this research as reference.

(1) Because the initial cost for setting up an e-Cloud classrom is relatively large, ahospital in job education wishing to set up e-Cloud classroom should evaluate its demand and future effects cautiously in advance. Besides, such planning will be more benefical and produce noticeable effects when the demand of the entire campus is considered. 
(2) The establishment of the e-Cloud classroom can integrate the teaching resources, bolster the functions of classrooms, cut waste, and lower costs.

(3) During the promotion of the e-Learning process, the researchers found out e-Cloud classroom is an ideal teaching tool. But it could not substitute entirely the complete courses. So, it is suggested that the e-Cloud teaching be used as an aid to traditional teaching or network learning platform.

\section{REFERENCES}

[1] Tsai H C, Wu J T 2007. A Study of Distance Laboratory Applied to the E-Learning Platform in Universities, Instructional Technology \& Media, 79:70-85.

[2] Jian Y, Lu J Y 2010. The Inspiration of Cloud Computing and Ubiquitous Learning To Digital Learning of the Public Sector, Training \& Development Fashion QuarterlyJjournal, 91: 67-73.

[3] Yu C P 2010. Future Campus Architecture from Cloud Technology Perspective. 2010 hospital in job education Architecture:hospital in job education Campus Ecological Implementation, 294-306.

[4] Huang B L 2001. Corporate Training Viewed From Online Learning Development, e-Enterprise, Manager's Report, 19: 12-23.

[5] Lin C C,Li H Y 2003. A study of Media Delivery for Web-Based Instruction, Instructional Technology \& Media, 65: 34-58.

[6] Gallagher J 1987. A summary of research in science education, Science Education, 71(3):307-457.

[7] Weng J L 2003. Realm of Advanced Digital Learning - How Enterprises Utilize e-Learning Technology, to Implement Real-World Simulation Training, e-Enterprise: Manager's Report, 48: 7075.

Table1. Construct Analysis of Respondents' Comparison of Network Learning Platform and e-Cloud Classroom

\begin{tabular}{|c|c|c|c|c|}
\hline \multirow{2}{*}{ Construct } & \multicolumn{2}{|c|}{ Mean Value } & \multicolumn{2}{c|}{ Standard Difference } \\
\cline { 2 - 5 } & $\begin{array}{c}\text { Network } \\
\text { Learning } \\
\text { Platform }\end{array}$ & $\begin{array}{c}\text { E-Cloud } \\
\text { Classroom }\end{array}$ & $\begin{array}{c}\text { Network } \\
\text { Learning } \\
\text { Platform }\end{array}$ & $\begin{array}{c}\text { E-Cloud } \\
\text { Classroom }\end{array}$ \\
\hline Familiarity & 3.16 & 3.64 & 0.842 & 0.942 \\
\hline Convenience & 2.76 & 2.84 & 0.960 & 0.866 \\
\hline Function & 2.52 & 3.68 & 0.646 & 0.844 \\
\hline Need & 2.38 & 3.88 & 0.725 & 0.918 \\
\hline Operation & 2.48 & 3.66 & 0.735 & 0.798 \\
\hline Learning motivation & 2.58 & 4.10 & 0.702 & 0.763 \\
\hline Helpfulness & 2.18 & 4.46 & 0.962 & 0.734 \\
\hline Satisfaction & 2.50 & 3.70 & 0.863 & 0.763 \\
\hline Learning effectiveness & 2.78 & 4.12 & 0.840 & 0.824 \\
\hline
\end{tabular}

